Simone Oliveira'

Marcello Santos Rezende ${ }^{2}$

Jussara Brito ${ }^{3}$

${ }^{1}$ Doutoranda da Escola Nacional de Saúde Pública, Fundação Oswaldo Cruz, Rio de Janeiro, Brasil.

${ }^{2}$ Mestrando da Escola Nacional de Saúde Pública, Fundação Oswaldo Cruz, Rio de Janeiro, Brasil.

${ }^{3}$ Professora pesquisadora da Escola Nacional de Saúde Pública, Fundação Oswaldo Cruz, Rio de Janeiro, Brasil.

\section{Saberes e estratégias dos operadores de telemarketing frente às adversidades do trabalho}

\author{
Telemarketing operators' practical \\ knowledge and strategies towards ad- \\ versities at work
}

\begin{abstract}
Resumo
Pretendemos contribuir para dar visibilidade aos saberes e estratégias desenvolvidos pelos operadores de telemarketing para lidarem com as situações nocivas e adversas no trabalho. Visamos indicar caminhos mais efetivos para as mudanças que são necessárias no processo de trabalho das centrais de atendimento. Como material de análise, optamos por utilizar entrevistas com dois operadores pertencentes a empresas de telefonia celular de grande porte localizadas no Rio de Janeiro, vinculados, porém, a centrais de atendimento diferentes. Nas entrevistas, buscamos nos aproximar da técnica de "instruções ao sósia" proposta por Oddone e Clot. Para análise, recorremos a conceitos da Ergonomia da Atividade, da Clínica da Atividade, da Psicodinâmica do Trabalho, do Modelo de Competências de Zarifian e da perspectiva ergológica. Observamos que, para tornar o trabalho "vivível" frente às adversidades e simultaneamente garantir o resultado esperado, os trabalhadores chegam antes do horário, driblam as "pausas", escolhem entre ficar ou sair do script, criam expressões verbais, conseguem tempos não previstos e se apóiam no coletivo de trabalho.
\end{abstract}

Palavras-chaves: telemarketing, atividade de trabalho, saúde do trabalhador, serviços.

\begin{abstract}
This article is intended to help outlining the telemarketing operators' practical knowledge and the strategies pursued by them to cope with possible hazards and adverse situations at work. It is also aimed at pointing out more effective ways of promoting the changes that must be introduced to improve working conditions at call centers. Data were collected by interviewing two operators from two different call centers, both employed at large cellular phone companies located in the city of Rio de Janeiro, Brazil. The interviews followed the "instructions for the double" approach, proposed by I. Oddone and Y. Clot. The concepts of Activity Ergonomics, Activity Clinic, Work Psychodynamic, Zarifian's "Competence Model" as well as the Ergological perspective were used for data analysis. The results showed that, in order to fight adversity at work and achieve what is expected from them, workers usually arrive before working hours, "cheat" the breaks, choose between following or not following the work script, create verbal expressions, manage to get unforeseen extra time and rely on their work group.
\end{abstract}

Keywords: telemarketing, work practice, worker's health, services. 


\section{Introdução}

No contexto da globalização, com a crescente importância de transações econômicas focalizadas na informação e no conhecimento, as inovações tecnológicas ocupam um lugar privilegiado no cenário produtivo, com uma acelerada mudança qualitativa em produtos e serviços. Essa característica é acompanhada pelo aumento da importância do setor de serviços, que paulatinamente passa a ser também predominante na economia. Neste setor, as telecomunicações ganham destaque, com intensa apropriação dos avanços tecnológicos.

No setor de telecomunicações é que surge, na década de 1980, a atividade nomeada pelo termo telemarketing, um canal para oferecer informações e serviços e receber críticas e sugestões dos clientes, servindo ainda como um veículo de propaganda, divulgando produtos e serviços de forma rápida através do aparelho telefônico. Surge para atender uma nova demanda de qualidade da produção com uma diversidade de produtos, com atendimento personalizado, além de uma produção vinculada à necessidade, no tempo certo. Busca responder a uma mudança de atitude dos consumidores, que passam a ter necessidade de suporte ao longo da vida útil do produto, formalizando uma interligação entre produto e serviço, uma vez que, quando se adquire um produto, adquire-se também um serviço. Para isso, essa atividade se apresenta através de vários formatos operacionais, tendo como tarefa o fornecimento de produtos, informações e serviços e o atendimento, diretamente e melhor, ao cliente, recebendo críticas e sugestões. Ou seja, um trabalho de caráter ativo para o setor de vendas e receptivo nas centrais de atendimento, as denominadas SAC - Serviço de Atendimento ao Consumidor. O setor vem representando um elo de ligação importante entre as organizações e os clientes e entre a produção (seja de produtos, seja de serviços) e o público em geral (seja a própria empresa, sejam outras empresas, sejam pessoas). Para a Associação Brasileira de Telemarketing - ABT (2006), que define telemarketing como "toda e qualquer atividade desenvolvida através de sistemas de telemática e multimídia, objetivando ações padronizadas e contínuas de marketing”, atualmente no Brasil são 580 mil trabalhadores envolvidos neste setor.
Na Inglaterra, esse tipo de atividade já emprega mais funcionários diretos do que as indústrias de carvão, aço e automobilísticas reunidas. Em uma estimativa realizada em 2002, havia 5 milhões de pessoas empregadas em call center nos Estados Unidos e aproximadamente 1,5 milhão na Europa (TOOMINGAS et al., 2002).

O telemarketing trata-se, então, de um diálogo em tempo real à distância, de forma padronizada e sistemática, com o intuito de estreitar relacionamentos e realizar negócios, existindo para isso quatro tipos: o ativo, o receptivo, o misto e o híbrido (MONTEIRO, 1997). Apesar do uso indiscriminado dos termos telemarketing, teleatendimento, central de atendimento, call center etc., verifica-se uma tentativa por parte dos profissionais da área de padronizar o termo relativo a esta atividade como telemarketing e as instalações como central de atendimento ou call centers (MÁRQUEZ, 2002).

Conectando informática e telefonia, a necessidade das empresas de se posicionarem no segmento da proximidade com o cliente (segmento identificado como um fator essencial da concorrência) faz das centrais de atendimento um lugar chave na melhoria da relação cliente-empresa, de caráter estratégico pela sua capacidade de captar informações que emanam do mundo da demanda (RUZZA \& FRANCIOSI, 2003).

Especificamente no que se refere à telefonia celular, é um dos serviços que mais cresce no mundo. No Brasil, o número de aparelhos celulares ultrapassa o de telefones fixos. Este mercado altamente competitivo, pela grande quantidade de empresas que torna a disputa pelos consumidores cada vez mais acirrada, passa a realizar constantes promoções, lançamentos de serviços ou produtos na busca de atender o cliente da melhor forma possível. As empresas têm que trabalhar para manter ou aumentar a lealdade dos usuários, cada vez mais exigentes na procura de serviços aprimorados, contínuos e seguros. Conseqüentemente, estas demandas recaem objetivamente sobre os operadores de telemarketing que, com rapidez, devem responder a estas variabilidades.

Por trás desse "paraíso" tecnológico e organizacional se desenha, entretanto, uma outra realidade. Instituições de pes- 
quisa e sindicatos de diversos países da Europa (Alemanha, Bélgica, Itália, França, Inglaterra e outros) criaram, em 1999, um "quadro de observação social dos call centers" que demonstrou que esse tipo de organização tornou-se sinônimo de uma forma moderna de degradação das condições de trabalho e baixa proteção jurídica dos trabalhadores. Taylorização, estresse, baixas remunerações e precarização da mão-deobra são algumas das palavras-chaves ligadas a esse setor (BUSCATTO, 2002).

De uma maneira geral, as centrais de atendimento são submetidas a uma medida muito precisa e intensa da produtividade que vem favorecendo o aparecimento de diversos problemas de saúde para seus operadores, como disfonias vocais e auditivas, lesões por esforços repetitivos e sofrimento mental, conforme evidenciado em diversos estudos (BRASIL, 2005).

$\mathrm{Na}$ perspectiva de contribuir para a compreensão das relações saúde-trabalho, este estudo busca dar visibilidade às estratégias que os operadores elaboram na atividade, lugar privilegiado para construção da saúde. Saúde aqui entendida como a capacidade de instaurar novas normas em situações adversas, portanto não reduzida a um equilíbrio ou capacidade adaptativa, aproximando-se da compreensão de Canguilhem (1999) de que a saúde se constitui na forma pela qual o sujeito interage com os eventos da vida ao longo de sua existência.

\section{A relação saúde-trabalho: a perspectiva deste estudo}

Partindo das reflexões de Canguilhem e dos estudos da Ergonomia, Schwartz (2000b) afirma que o meio de trabalho é sempre, de alguma forma, infiel. Essa infidelidade deve ser gerida pelos trabalhadores não simplesmente como uma execução, mas por um uso de si. Isso quer dizer que o trabalhador necessita mobilizar suas capacidades, recursos e escolhas para dar conta dessa infidelidade. A escolha é necessária porque as instruções contêm equívocos e são insuficientes para lidar com as variabilidades e o acaso. A maneira de cobrir esse déficit de normas será inevitavelmente uma maneira pessoal, uma tentativa de recentrar o meio em torno de sua própria história, normas e valores, ocorrendo assim um "debate de normas e valores". Ao fazerem uso de si, os trabalhadores desenvolvem saberes, e é nesse sentido que apontam as pesquisas realizadas por Cru \& Dejours (1987) sobre os saberes de prudência. Segundo esses pesquisadores, o saber dos operários é maior do que freqüentemente se crê.

Cru \& Dejours formularam a hipótese, radicalmente oposta aos discursos habituais sobre a prevenção, segundo a qual os trabalhadores conhecem em profundidade os perigos de seu trabalho e que provavelmente se defendem espontaneamente (de um modo não perceptível pela organização do trabalho) não somente contra o medo (papel das ideologias defensivas da profissão), mas também contra os próprios riscos; e defendem-se concretamente, com a ajuda de procedimentos específicos eficazes, no decorrer do trabalho.
Para Schwartz (2000a), do mesmo modo que é impossível manter a estabilidade do meio em que vivemos, que é impossível eliminar as variabilidades desse meio (conforme evidenciou a Ergonomia da Atividade), não se pode viver (é "invivível”) sob um regime de total imposição deste meio, isto é, de suas normas. O impossível convoca um ser apto a gerir as adversidades do meio. Frente às normas impostas (antecedentes), os trabalhadores - para tornarem o meio vivível - criam estratégias em um movimento contínuo de renormatização ${ }^{4}$. Não se limitando a procedimentos dirigidos à regulação do processo, o trabalhador tenta modificar o meio de trabalho (inclusive as prescrições) mesmo que em escala infinitesimal, com renormatizações que são orientadas pela busca de saúde (incluindo formas de defesa contra as adversidades).

Sem dúvida, as condições adversas de trabalho no setor de telemarketing, envolvendo problemas relativos à organização prescrita do trabalho, exigem estudos de diversos tipos e enfoques. A contribuição que pretendemos dar é identificar estratégias criadas pelos operadores para lidarem com essas situações com a perspectiva de detectar problemas que eles tentam driblar/ contornar ou evitar (através de renormatizações e do desenvolvimento de saberes), mas que são dificilmente reconhecíveis por observadores externos. Os saberes desenvolvidos pelos trabalhadores são muitas vezes "invisíveis" não só para a organização do trabalho, mas também para os próprios trabalhadores - que os desenvolvem em grande parte de forma não consciente.
${ }^{4}$ Optamos, neste artigo, pela tradução do conceito de "renormalization" por "renormatização" (e não "renormalização" como encontramos em outros textos) após diálogos com o autor, tendo em vista enfatizar a visão vitalista aí presente, isto é, a capacidade humana de criar novas normas de vida (ou simplesmente, conforme expressão de Canguilhem, normatividade). A expressão "renormalização", em português, pode dar a falsa idéia de retorno à normalidade. 
Avaliamos, portanto, que dar visibilidade a essa criação cotidiana dos operadores pode fornecer pistas e indicar caminhos mais efetivos para as mudanças que são necessárias no processo de trabalho das centrais de atendimento e que propostas de prevenção que não levem em consideração a experiência dos trabalhadores podem encontrar di-

\section{Metodologia}

A atividade de trabalho é "sempre tentativa, mais ou menos individual, mais ou menos coletiva, de reinventar maneiras de fazer, maneiras de viver as contradições, as restrições, os recursos do presente" (SCHWARTZ, 2002). Para compreender essa afirmação, é necessário partirmos daquilo que a Ergonomia da Atividade chama de defasagem entre o trabalho prescrito e o trabalho real (MONTMOLLIN, 1990; DANIELLOU et al., 1989). O trabalho prescrito são os objetivos postos ao trabalhador por instâncias exteriores a ele mesmo. $\mathrm{O}$ trabalho real, aquele que é efetivamente realizado, jamais corresponde ao trabalho prescrito. Segundo Guérin et al. (2001), a Ergonomia da Atividade considera que essa distância se dá principalmente pela existência de variabilidades nas situações de trabalho: variabilidade humana (inter e intra-individual) e variabilidades externas (do sistema técnico e organizacional, como imprevistos e disfuncionamentos). Por mais que se busque eliminar as variabilidades das situações de trabalho, nunca é possível tornar as condições de produção perfeitamente estáveis. Nesse sentido, a atividade de trabalho compreende aquilo que deve ser ajustado, rearranjado, inventado pelos trabalhadores para dar conta dos objetivos fixados pela tarefa. A atividade de trabalho é o elemento central organizador e estruturante da situação de trabalho (GUÉRIN et al., 2001).

Para o psicólogo do trabalho Yves Clot (1999), frente a essa defasagem entre o trabalho prescrito e o trabalho real, os trabalhadores tomam decisões muitas vezes não-conscientes, de forma que os mecanismos de produção dessa atividade muitas vezes não são diretamente observáveis. Define como real da atividade isso que vai além do visivelmente observável: "o real da atividade é também aquilo que não se faz, o que não podemos fazer, o que procuramos fazer sem conseguir - os fracassos -, o que gostaríamos ou poderíamos fazer, o ficuldades de serem implementadas. Por outro lado, pressupomos que essas estratégias sinalizam adversidades enfrentadas pelos trabalhadores que são potencialmente geradoras de agravos. Lembremos que, para Schwartz (2003), falar de trabalho a partir dos debates de normas permite colocar o dedo naquilo que pode mudar.

que a gente pensa ou sonha poder fazer" (CLOT, 1999, p. 119).

Para ter acesso a esse real, Clot (1999) desenvolve a técnica de "instruções ao sósia" - baseada nos trabalhos de Oddone et al. (1981). Essa técnica foi elaborada no contexto da reforma sanitária italiana nos anos 1970 para ser utilizada conjuntamente aos operários da Fiat com o intuito de compreender melhor a relação saúde-trabalho nas fábricas. O exercício de "instruções ao sósia” implicava em um trabalho no qual o pesquisador perguntava a um operário: "Suponha que eu seja seu sósia e que amanhã eu vou substituí-lo no seu trabalho. Quais são as instruções você deve me transmitir a fim de que ninguém perceba essa substituição?" Delimitava-se então uma seqüência de trabalho determinada para facilitar a focalização da experimentação sobre os "detalhes do trabalho", interessando-se, a princípio, mais sobre a questão do como do que sobre o porquê daquela atividade. Oddone et al. (1981) elaborou essa técnica porque havia observado que quando os operários eram simplesmente solicitados a falar sobre seu trabalho, eles tendiam a reproduzir um comportamento ideal, de acordo com o prescrito, tendo pouco a ver com o trabalho real. A utilização dessa técnica permitia que os trabalhadores percebessem que existe uma defasagem entre o modelo teórico da empresa e o modelo prático de produção que só podia ser ultrapassada pela intervenção deles mesmos.

Como material de análise, optamos por utilizar entrevistas realizadas com dois operadores vinculados a centrais de atendimento diferentes, mas em ambos os casos pertencentes a empresas de telefonia celular de grande porte localizadas no Rio de Janeiro. Aos dois operadores foi explicado anteriormente o que procurávamos investigar. No início da entrevista de "instruções ao sósia”, fazíamos a pergunta disparadora: "suponha que eu seja seu sósia..." A partir daí, procurávamos nos colocar em uma 
postura de aprendiz, perguntando todos os imprevistos e obstáculos que surgiriam na situação de trabalho, buscando apreender o máximo de instruções possíveis, como se fôssemos de fato substituí-los no dia seguinte. As entrevistas foram realizadas fora do ambiente da empresa e duraram aproximadamente uma hora. Foram gravadas, transcritas e depois analisadas.

Entendemos que esta abordagem permitiu que os operadores reencontrassem suas hesitações e debates de si consigo, revelando a gênese de suas escolhas. Ao formalizar um modo de elaborar a experiência e transmiti-las a um suposto substituto, os operadores reliam a sua realidade e refletiam sobre a atividade e as condições de trabalho. Isso permitiu que nos aproximássemos de suas estratégias e das singularidades das situações de trabalho em que se encontram.

Este estudo procura se aproximar dos debates de normas e valores presentes na

\section{Resultados e discussão}

Singularizações das situações de trabalho: entre prescrições, normas e valores

Nas duas empresas (A e B), a jornada de trabalho dos operadores é de 6 horas com uma pausa de 15 minutos para lanche e mais 5 minutos para ir ao banheiro na empresa A e sete minutos na empresa B. Na empresa B, o setor ao qual pertence o operador entrevistado é de caráter receptivo, atende a empresas, sendo denominado corporativo, e exige mais experiência dos atendentes. Este operador trabalha na empresa há aproximadamente sete anos, contrariando uma das características do telemarketing que é a alta rotatividade (em média a permanência gira em torno de dois anos). Na empresa A, o setor ao qual pertence o operador entrevistado também é de caráter receptivo, atendendo, no entanto, a clientes que possuem celular pré-pago. O operador trabalha na empresa há um ano.

Nestas empresas, o serviço de atendimento objetiva solucionar dúvidas e orientar seus clientes na utilização de um serviço, o que implica mobilizar capacidade de escuta e comunicação, visando a compensar as diferenças culturais entre um cliente e outro, e ainda a capacidade de reverter as manifestações agressivas demonstradas pelos clientes insatisfeitos. Os operadores estão submetidos a uma série de mecanismos atividade desses operadores, entendendo que a análise desses debates pode esclarecer como se constituem os saberes e as estratégias elaboradas por eles, ajudandonos a compreender como se constitui e como se podem transformar as situações sob as quais opera aquela atividade. O uso de conceitos de diferentes disciplinas ao longo deste estudo se deve ao fato deles colaborarem para que a análise abarque a complexidade dos processos envolvidos. Por exemplo, da Psicodinâmica do Trabalho recorremos a alguns conceitos que se mostram eficazes para a compreensão dos coletivos de trabalho. Da Sociologia do Trabalho utilizamos o conceito de competência desenvolvido por Zarifian (2001). O conceito de atividade aqui adotado se inspira na Ergonomia da Atividade, mas também na Clínica da Atividade e na Ergologia. Os conceitos-ferramenta a que recorremos se mostraram coerentes e complementares, apesar de suas especificidades teóricas.

de controle no trabalho: controle de tempo, do conteúdo da informação prestada e dos resultados obtidos. Os mecanismos que operam o controle são múltiplos: registro de cada atendimento pelos próprios operadores no sistema eletrônico específico e escutas telefônicas dos atendimentos em tempo real pelos trabalhadores da "monitoria”. Semanalmente são emitidas avaliações individuais que indicam a qualidade do atendimento de acordo com os parâmetros das empresas: rapidez na identificação da demanda do cliente, dicção, empatia, tom de voz, atenção/interesse, tempo médio de atendimento (TMA), adequação ao script, entre outros.

A avaliação é divulgada internamente por meio de quadrante e cores, em que o maior nível é o quadrante verde, que significa $100 \%$. A meta na empresa B é atingir 90\% nesta avaliação. Este percentual varia de empresa para empresa e de setor para setor. A forma como está organizada a contagem de pontos pela monitoria é motivo de grande insatisfação como pode ser observado na seguinte fala:

Essa tabela começa com cem e conforme você erra vai diminuindo seus pontos. Aí eu disse assim: vem cá, então ficam caçando erros para poder me diminuir pontos? Não procuram os meus acertos. Se eu já começo com cem, eu estou com cem por 
cento de acerto, então têm que procurar erros para diminuir isso. Você tem que falar o nome do cliente três vezes, no início, durante a ligação e no final, se você não falar isso, você perde ponto.

Nessa fala, percebemos um debate de valores, pois o operador aponta uma prescrição que ele considera intangível: tanto a empresa B como a empresa A partem do princípio de que os operadores devem permanecer nos $100 \%$ e qualquer erro é um desvio desse padrão idealizado. O operador da empresa B questiona essa lógica alegando que em outras situações da vida em que somos avaliados, o foco da avaliação parte do zero e se concentra em nossos acertos. Está aí uma contradição fundamental: a norma que rege a organização do trabalho é apontar e contabilizar os erros dos operadores de tal forma que seus acertos e competências jamais sejam reconhecidos, enquanto os trabalhadores entendem que seus (muitos) acertos deveriam ser a referência. Para as empresas, a norma é não errar, de acordo com os valores mercantis/ mensuráveis no qual se baseiam; para os trabalhadores, a norma seguida é procurar acertar, em consonância com valores de outro tipo, que Schwartz (2000a) chama de valores sem dimensão.

Chegar antes do horário e driblar as "pausas": estratégias para lidar com o ritmo intenso de trabalho

Para o operador da empresa A, uma importante estratégia criada para lidar com o trabalho é chegar mais cedo, em torno de 30 minutos antes do horário, para "relaxar", preparar-se antes de começar os atendimentos. Nesse período anterior, eles conversam com os colegas, vão ao banheiro ou simplesmente ficam sentados em sua posição de atendimento (PA) aguardado o início do horário oficial. Encaramos esses atos como uma estratégia para enfrentar a tarefa sem se cansar demasiadamente, conforme podemos observar na seguinte fala:

Se eu chego em cima da hora, 10 minutos pra me logar, eu não me logo a mesma pessoa, me logo cansada, sei lá, parece que foi tudo muito corrido.

Nas duas empresas, as "pausas-lanche" são organizadas por escalas semanais, em que se estabelece o horário diário para sua utilização. A “pausa-banheiro” é utilizada no momento de necessidade. No entanto, apesar do controle intenso sobre o trabalho dos operadores, eles encontram maneiras de driblar a forma prescrita do uso de pausas. Uma estratégia muito utilizada é guardar as "pausas" até o final da jornada, deixando para tirá-la nos minutos finais, dando um tempo para se organizar e se recompor do trabalho antes de sair da empresa:

Faltam 10 minutos para eu sair e eu não tirei a minha "pausa-lanche" ou não tirei minha "pausa-banheiro". Nesses minutos, eu consigo arrumar minhas coisas, ir ao banheiro e, quando dá meio-dia em ponto, desligo o telefone e me "deslogo". E a maioria faz isso, até para você descansar um pouco mais.

Outra maneira encontrada é a de utilizar a "pausa” após uma ligação considerada cansativa e "estressante". Neste caso, o operador não se levanta do posto e vigia a supervisora para que ela não perceba que ele está em "pausa":

Porque você está lá numa ligação estressante pensando "eu ainda não tirei minha 'pausa-lanche', mas ainda não está na minha hora”. Se ela está lá sentada, não está circulando, dá a "pausa", para uns três, quatro minutos, já dá um alivio. Tem que ficar ali mesmo e dar uma relaxada, conversa com colega ou entra na internet (...).

Sair ou ficar no script: estratégias para garantir a produção e tornar vivível o trabalho

Os operadores devem seguir um script, que normalmente possui: uma abertura, um desenvolvimento e uma finalização. Nas duas empresas, ao atender a ligação, o operador deve identificar-se (dizer nome e sobrenome); deve repetir o nome do cliente no mínimo três vezes (no início, durante a ligação e no final). Quando solicitar um tempo de espera ao cliente, deve dizer "só um momento por gentileza” e colocá-lo para aguardar. Ao retornar deve falar: "senhor/a x, obrigado por aguardar”. Ao final da ligação deve dizer: "ficou alguma dúvida?” e agradecer: "a empresa y agradece a sua ligação".

Notamos que o script fornecido pelas empresas muitas vezes é inadequado ou insuficiente para que os operadores respondam as dúvidas dos clientes, exigindo mobilização constante e inventividade para informar corretamente. Os operadores relatam:

Muitas vezes devemos mudar a forma que estamos utilizando para informar o cliente. Eu costumo usar exemplos que nós temos no nosso dia-a-dia pra ele tentar entender. 
Como dar conta das exigências de produtividade senão transgredindo a prescrição de seguir o script? Para que a produção se realize no tempo permitido, essa atividade de trabalho requer recursos e capacidades mais vastos que aqueles explicitados pela empresa.

Ao relatar uma situação em que não seguiu todas as normas e conseguiu solucionar o problema apresentado pelo cliente, o operador da empresa B dá um exemplo em que, na avaliação da monitoria, tirou 63 pontos. Nesta ligação, ele considera que deveria ter tirado 100, pois este cliente já havia entrado em contato com a central quatro vezes, sem obter resultados. Ao final, o cliente demonstrou extrema satisfação com o atendimento. A incoerência da avaliação fica explicitada pela seguinte fala do operador:

Me pontuam por não falar o nome dele, por não sei o quê, e ele nem ligou para isso. Se fosse por eu não falar o nome dele em momento algum, ou se eu fui grosso com ele apesar de ter resolvido o problema, aí é uma situação. Mas não aconteceu nada disso. Essa ligação para mim é 100. Por isso que eu falo, essa monitoria para mim e nada é a mesma coisa. Não adianta você ficar me pontuando em besteira.

Com a preocupação de seguir uma prescrição rígida, a hierarquia ignora o esforço e a responsabilidade do operador na busca de solucionar o problema do cliente. Além de seguir o script, a satisfação do cliente e a obtenção de resultados também são prescrições. Estaríamos aqui diante de prescrições contraditórias? Os trabalhadores buscam realizar da melhor forma possível sua tarefa e atingir os objetivos fixados pela organização desde que sejam coerentes e não descabidos, de acordo com Dejours (2004).

A rigidez e a contradição dos critérios de avaliação podem levar também os operadores a optarem por se manterem estritamente no script.

Então eu comecei a tirar nota boa porque eu comecei a fazer isso, e assim eu estou pouco me importando se o cliente está com problema ou não. Eu quero é tirar meu cenzinho, né? Eu tirei 100 porque eu falei igual a um papagaio. Posso até não ter resolvido o problema do cliente, mas eu fiz igual a um papagaio.

Essa situação pode levar a um distanciamento entre o operador e a qualidade do seu atendimento e do serviço prestado, rompendo dessa forma com a produção de sentido daquele trabalho. Essa perda de sentido pode gerar um sofrimento a partir da atividade que é contrariada. É uma amputação do poder de agir. Segundo Ricoeur (apud CLOT, 1999), o sofrimento não é unicamente definido pela dor psíquica ou mental, mas "pela diminuição, através da destruição da capacidade de agir, do poderfazer, sentido como um atentado à integridade de si”.

Se de um lado os trabalhadores fazem escolhas em função de valores, de outra parte essas escolhas são arriscadas. Antecipam soluções possíveis sabendo que efetivamente há um risco de falhar, de criar dificuldades novas, de desagradar outras pessoas. Escolher uma ou outra opção, uma ou outra hipótese é uma maneira de escolher por si mesmo e ter que assumir as conseqüências. Logo, a atividade de trabalho tem algo de dramático. Isso nos reenvia ao que Schwartz (2000b) chama de dramáticas de uso de si.

\section{Criação de expressões verbais: estratégias para garantir o "TMA"}

Uma das exigências de produtividade cobrada pelas empresas é o TMA. Outra exigência é que o operador nunca termine a ligação, pois deve esperar o cliente fazêlo. Que palavras usar para que o atendimento não se prolongue? Os entrevistados relataram que criam expressões ou usam o tom de voz para evitar que o atendimento dure mais tempo do que o exigido: "Não pergunte 'algo mais?' porque, embora ele (o cliente) não tenha o que perguntar, ele vai criar. Eu costumo às vezes perguntar 'o senhor compreendeu a informação?’” Nessa fala, percebe-se claramente o uso da linguagem como instrumento de trabalho. Se tomarmos isoladamente a seqüência de palavras "o senhor compreendeu a informação?”, estamos no universo da significação literal. Entretanto, o sentido que se constrói no contexto desta situação específica de trabalho subentende um ato de encerrar o atendimento telefônico.

Outra estratégia de lidarem com o TMA é a forma de registrarem a chamada no sistema. Quando não conseguem fazer o registro da chamada dentro do período de uma ligação, registram-na no atendimento seguinte enquanto ouvem o novo cliente.

Muitas vezes você até ouve o que ele está falando, mas não assimila. Aí o que você faz? Você diz assim: 'Qual o número do seu telefone?' Aí ele diz o número. 'O senhor gostaria de saber sobre a conta, não 
é isso?'- 'Não, a conta eu já tive a informação. E eu quero saber disso...'

Nessa situação, observamos que o operador, de forma sutil, leva o cliente a repetir sua demanda sem deixar claro que não a havia assimilado. Além de cumprir o TMA, o operador deve cumprir uma outra prescrição: estar atento à fala do cliente. A monitoria também penaliza quando o operador demonstra claramente que não prestou atenção no atendimento. Desta forma, ele tenta despistar a monitoria buscando recursos verbais ("não é isso?”).

\section{Coletivo de trabalho: estratégia de apoio e evitação de erros}

Para que o trabalho seja efetuado, há a presença indispensável da cooperação dos colegas, embora a avaliação sobre os resultados pese individualmente para cada trabalhador. O operador poucas vezes se encontra só diante de seu trabalho, conforme podemos observar nesta fala:

Você deve sempre sentar perto de pessoas conhecidas e, se não for conhecida, passa a conhecer. Porque são pessoas que podem te ajudar, até mesmo quando não tem ligação, conversar, distrair.

Ajudar, nesse caso, refere-se tanto a uma informação técnica que colegas mais experientes possam fornecer, evitando dar informações erradas, quanto a um apoio em momentos críticos (cliente agressivo, por exemplo).

Tais regras são fruto da dinâmica dos coletivos informais que se apóiam na sabedoria prática dos trabalhadores, exercendo, desta forma, um papel na defesa contra os riscos e o medo (DEJOURS, 1993).

Para Zarifian (2001) uma das características da noção moderna de competência é a capacidade de mobilizar redes de atores em torno das mesmas situações e fazer com que esses atores compartilhem as implicações de suas ações:

\begin{abstract}
Se você não achar a informação e ficar nervoso sem conseguir responder, você vai perguntar ao operador do seu lado, se ele não souber você liga pra supervisão; não tendo o procedimento, abre lá a categorização onde será encaminhado para o setor específico. Você também está sempre olhando pra PA (posição de atendimento) do outro, principalmente quando ele está atendendo, eu vivo o tempo todo em carrapato. Carrapato é o termo que a gente usa quando a gente tá entrando, tendo treinamento, então a gente fica ao lado de um operador que está atendendo pra ver como é o procedimento, pra ver como fazer. Eu vivo fazendo carrapato com os meus amigos do lado.
\end{abstract}

Vemos nessa fala que os laços entre os trabalhadores se tecem na cooperação, face às dificuldades reais enfrentadas na situação específica de trabalho. Embora grande parte das empresas de telemarketing, com seus mecanismos de gestão e de controle, dificultem a mobilização dessa competência, podemos constatar que a cooperação no atendimento telefônico é com freqüencia efetuada informalmente para regular diferentes modalidades de ajustamento, colocadas em prática pelos diferentes operadores no desafio de preencher as lacunas do trabalho e prever futuros imprevistos (viver fazendo "carrapatos").

\section{Comentários finais}

A aproximação com a técnica de "instruções ao sósia” possibilitou perceber que a atividade de verbalização neste caso difere dos dados produzidos em entrevistas tradicionais, pois permite uma maior aproximação ao que Clot (1999) chama de real da atividade. A elaboração e a formalização da experiência acontece à medida que o trabalhador, em diálogo com o pesquisador, se confronta com os numerosos problemas que o tocam pessoalmente em sua atividade.

Como vimos, os operadores indicaram uma contradição fundamental presente na atividade de telemarketing, expressa atra- vés de uma prescrição impossível de ser atingida: não errar. Mesmo que eles tentem acertar e fazer o melhor que podem, não são seus acertos que são contabilizados, mas seus erros - erros que na verdade podem ser justamente a solução dos problemas apresentados pelos clientes. Em outras palavras, o que é considerado erro é tudo aquilo que não corresponde ao que foi prescrito, mesmo que o resultado alcançado seja satisfatório. Podemos acrescentar: o que o trabalhador entende como erro não corresponde à compreensão/norma da empresa. Dissemos que esta é uma contradição fundamental porque ela parece se configurar numa adversidade do processo 
de trabalho para o qual os operadores não encontram saídas. Pelo menos não foi possível identificar uma estratégia satisfatória dos operadores para lidarem com tal adversidade.

Entretanto, identificamos saberes e estratégias que os ajudam a enfrentar outras adversidades. Todas apontam a necessidade dos trabalhadores ampliarem a possibilidade de uso de sua experiência. Percebemos isso quando decidem chegar antes do horário, quando driblam as "pausas", quando optam por sair do script ou segui-lo, quando criam expressões verbais, quando forçam a criação de tempos não previstos, quando se apóiam no coletivo de trabalho para

\section{Referências bibliográficas}

ABT. Associação Brasileira de Telemarketing. $6^{a}$ pesquisa anual de telemarketing. Disponível em: www.abt.org.br/6_pesquisa_abt.htm. Acesso em: 07 fev. 2006.

BRASIL. Ministério do Trabalho e Emprego. Recomendação Técnica DSST n ${ }^{\circ} 1$, de 23 de março de 2005. Sobre segurança e saúde nas atividades de teleatendimento. Disponível em: www.mte.gov.br/Empregador/segsau/Legislacao/Recomendacoestecnicas/Conteudo/recomendacaotecnica012005.pdf. Acesso em: 07 fev. 2006.

BUSCATTO, M. Les Centres d'appels, usines modernes? Les rationalisations paradoxales de la relation teléphonique. Sociol. trav., v. 44, n. 1, p. 99-117, 2002.

CANGUILHEM, G. O normal e o patológico. Rio de Janeiro: Forense Universitária, 1999.

CLOT, Y. La fonction psychologique du travail. Paris: PUF, 1999.

CRU, D.; DEJOURS, C. Saberes de prudência nas profissões da construção civil. Rev. bras. saúde ocup., v. 15, n. 59, p. 30-34, 1987.

DANIELLOU, F.; LAVILLE, A.; TEIGER, C. Ficção e realidade do trabalho operário. Rev. bras. saúde ocup., v. 17, n. 68, p. 7-13, 1989.

DEJOURS, C. Inteligência operária e organização do trabalho: a propósito do modelo japonês de produção. In: HIRATA, H. (org.). Sobre o modelo japonês de automatização, novas formas de organização e de relações de trabalho. São Paulo: Edusp, 1993. p. 281-309.

Inteligência prática e sabedoria prática: duas dimensões desconhecidas do evitarem erros. Podemos afirmar que sem o uso que fazem do tempo, do script, de suas expressões verbais e da relação com os demais trabalhadores, a atividade de trabalho em telemarketing se tornaria ainda mais desgastante e dificilmente se alcançariam os resultados esperados. Essas são algumas pistas para mudanças na organização do trabalho, a serem discutidas e melhor avaliadas com os próprios operadores. Neste sentido, vimos realizando em parceria com o Sindicato dos Trabalhadores em Telecomunicações do Estado do Rio de Janeiro (SINTTEL-RJ) encontros para discussão da relação entre saúde e trabalho na atividade de telemarketing. trabalho. In: LANCMAN, S.; SZNELWAR, L. I. (orgs). Da psicopatologia à psicodinâmica do trabalho. Rio de Janeiro: Fiocruz, 2004. cap. 9.

GUÉRIN, F. et. al. Compreender o trabalho para transformá-lo: a prática da ergonomia. São Paulo: Edgard Blücher, 2001.

MARQUEZ, M. B. Carrapateando: uma análise psicossocial da atividade de telemarketing. 2002. Dissertação (Mestrado em Psicologia Social) - Faculdade de Psicologia, Universidade Católica de São Paulo, São Paulo, 2002.

MONTEIRO, N. A. Aspectos ergonômicos do trabalho em atividade de teleatendimento bancário. 1997. Dissertação (Mestrado), Universidade de Guarulhos, São Paulo, 1997.

MONTMOLLIN, M. L'Ergonomie. Paris: La Découverte, 1990.

ODDONE, I.; RE, A.; BRIANTE, G. Redécouvrir l'expérience ouvrière. Paris: Sociales, 1981.

RUZZA, R. Di; FRANCIOSI, C. La prescription du travail dans les centres d'appels telephoniques. Revue de I'IRES, n. 43, 2003/3.

SCHWARTZ, Y. Le paradigme ergologique ou un métier de Philosophe. Toulouse: Octarès Éditions, 2000a.

. Trabalho e uso de si. Revista Proposições, v. 11, n. 2, p. 34-50, 2000 b.

. A abordagem do trabalho reconfigura nossa relação com os saberes acadêmicos: as antecipações do trabalho. In: SOUZA-E-SILVA, M. C. P.; FAITA, D. (orgs.) Linguagem e trabalho: construções de obje- 
tos de análise no Brasil e na França. São Paulo: Cortez, 2002.

Synthèse des Journées. In: MARTIN, C.; BARADAT, D. (orgs.) Des pratiques en réflexion: dix ans de débats sur l'intervention ergonomique. Toulouse: Octarès Éditions, 2003.
TOOMINGAS, A. et al. Work condititions and employee health at call centers. Sweden: Departament of Occupational Medicine, Sundsvall Hospital, 2002.

ZARIFIAN, P. Objetivo competência: por uma nova lógica. São Paulo: Atlas, 2001. 